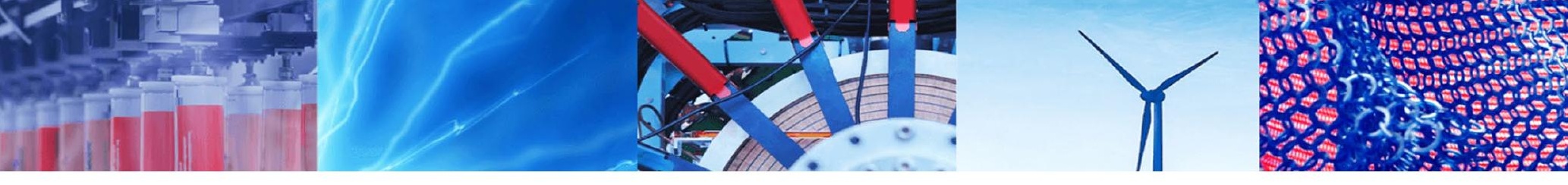

Research Article

\title{
Prediction of the voltage status of a three-phase induction motor using data mining algorithms
}

\author{
Aderibigbe Israel Adekitan ${ }^{1}$ (D) Ademola Abdulkareem ${ }^{2}$
}

Received: 13 August 2019 / Accepted: 18 November 2019/ Published online: 25 November 2019

(c) Springer Nature Switzerland AG 2019

\begin{abstract}
Data mining has found application in many research fields for predictive analysis. In engineering, data mining has been applied for equipment fault prediction by using the historical fault data of the equipment to train a data mining model for predicting future events. Power supply variations, and power quality issues affect the performance of a three-phase induction motor (TPIM). In this study, the operational performance data of a TPIM was deployed as a dataset for training a Konstanz Information Miner based model, for predicting the voltage status of the motor. The prevailing voltage status is classified into three, and these are: under voltage (2-10\%), rated voltage, or over voltage (2-10\%). For comparative analysis, the Tree Ensemble, Decision Tree, Random Forest and Support Vector Machine (SVM) were deployed for the voltage prediction. The result shows that the SVM had the highest prediction accuracy of $84.85 \%$. This creates a platform for developing embedded systems that are trained using knowledge acquired from data mining for performance monitoring of induction motors.
\end{abstract}

Keywords Machine learning · Data mining · Power supply variations · Power quality · Three phase induction motor · Knowledge discovery

\section{Introduction}

Drives are the back bone of most industrial processes, providing controlled motion of production line components and equipment. The three phase induction motor (TPIM) is the most used industrial motor due to its ruggedness, reliability and low maintenance requirements $[1,2]$. TPIM is designed to run on a balanced three phase power supply at the rated voltage level for optimal performance, reduced energy losses, and also to maximize the service life of the motor. According to Oyedepo et al. [3], and Quispe et al. [4], electric motors account for $40-70 \%$ of the total industrial energy consumption, and research has shown that energy consumption increases with economic growth rate. Consequently, with the anticipated economic growth in Africa, India and China from 2015 to 2040; a significant increase in industrial energy consumption is expected [5].

The gap between power generation and power demand increases daily, particularly in the developing countries, and this creates undue stress on the power supply network resulting in power quality and line disturbances which distorts, and causes deviation of the supply voltage or current from the ideal value and waveform. Power quality impairs the operational performance of TPIM, and various research studies have conducted analysis on the effects of unbalanced voltage on TPIM [6-8]. Voltage unbalance produces sequence current and pulsating sequence torque which increases motor losses and winding temperature with a tendency to cause local hot spots in the winding $[9,10]$.

\footnotetext{
$\triangle$ Aderibigbe Israel Adekitan, ade_kitan@yahoo.com | 'Department of Electrical Engineering and Information Technology, Technische Universität Ilmenau, Ilmenau, Germany. ${ }^{2}$ Department of Electrical and Information Engineering, Covenant University, Ota, Ogun State, Nigeria.
} 
Voltage unbalance reduces the efficiency of a TPIM as a result of increased losses and current harmonics [11], and this may ultimately reduce the life span of the TPIM.

Apart from voltage unbalance which has been extensively studied, balanced under voltage (UV) and balanced over voltage (OV) supply conditions are two extremes that negatively impact motor operational performance [12]. Voltage variation above and below the rated TPIM operational voltage induces torque pulsations which affect the reliability of the process where such a motor is installed. This may lead to bearing damage or any other related mechanical faults. According to De Oliveira et al. [12], and Awelewa et al. [13], the presence of power quality related issues on power supply systems is almost certain. This makes it important to ensure that power systems are adequately monitored, not just by the power distribution company but also within industries. Power quality monitoring will enable establishments to be aware when significant supply variations occur [14], in order to deploy adequate interventions toward preventing power-quality induced process reliability issues.

Over the years, researchers have applied different novel approaches for studying diverse operational aspects of the induction motor. In Glowacz et al. [15], acoustic signal generated during a motor operation was applied as a training data vector for detecting faults in single phase induction motors. Infrared thermography which has been extensively applied in studies on static machines was applied by López-Pérez and Antonino-Daviu [16] for predicting the operational failure of induction motors. In Sun et al. [17], a novel, sparse deep stacking network as an improved deep learning method which avoids over fitting was proposed, and applied for diagnosing motor faults. Likewise, artificial neural network has also been applied for predicting motor operational status and faults [18, 19], and for identifying voltage unbalance [20]. The study by Hsiao and Liu [21], further emphasized the importance of predictive diagnostic systems for monitoring the health of induction motors. This is currently the data era where emphasis is on knowledge discovery from dataset, and as such, this paper will investigate the feasibility of acquiring operational information for decision making from the dataset of a TPIM using data mining techniques.

A running TPIM generates series of operational performance data such as current, input power, reactive power, torque, air gap power and so forth. The magnitude and the pattern of a TPIM's operational parameter dataset is influenced by the nature of the power supply to which the motor is connected, and as such, the dataset contains vital information that may be identified as pointers to the prevailing supply scenario. This study proposes the use of data mining methods for voltage classification on a TPIM, and seeks to demonstrate the feasibility of achieving this using data pipeline workflow. In this study, data mining method was applied to the MATALB simulated operational TPIM dataset using KNIME (Konstanz Information Miner) Analytics application to develop a predictive data mining model, that identifies and classifies the nature of the supply voltage as being under voltage (2-10\%), balanced, or over voltage (2-10\%) based on the knowledge acquired by the model through training. Knowledge acquired from the data mining model can be deployed as a predictive model markup language (PMML) file for training intelligent modules for performance monitoring of induction motors.

\section{The three phase induction motor}

The rotor winding and the stator winding parameters are vital when analysing a three-phase induction motor. The simulated motor performance dataset in this study, is based on the following TPIM parameters: stator inductance $\mathrm{Xs}=0.1843 \Omega$, rotor inductance $\mathrm{Xr}=0.1843 \Omega$, mutual inductance $\mathrm{Xm}=4.8384 \Omega$, rotor resistance $\mathrm{Rr}=0.0908 \Omega$, stator resistance $\mathrm{Rs}=0.0774 \Omega$ and core resistance $\mathrm{Rc}=941$. Figure 1 shows the equivalent circuit diagram of a TPIM with the electrical motor parameters as indicated.

The manufacturers of TPIMs typically indicate the rated balanced voltage on the name plate, but due to operational realties, the voltage supply available for running TPIM often varies from the rated voltage value. In this study, the following voltage supply scenarios were considered: balanced under voltage supply condition (10\%UV, $8 \% \mathrm{UV}, 6 \% \mathrm{UV}, 4 \% \mathrm{UV}$, and $2 \% \mathrm{UV}$ ), balanced rated voltage condition (BV), and balanced over voltage supply condition ( $2 \% \mathrm{OV}, 4 \% \mathrm{OV}, 6 \% \mathrm{OV}, 8 \% \mathrm{OV}$, and $10 \% \mathrm{OV})$. The percentage deviation from the rated voltage is defined as follows:

$\%$ Voltage Variation $=\frac{\mid \text { Supply Voltage }- \text { Rated Voltage } \mid}{\text { Rated Voltage }} \times 100 \%$

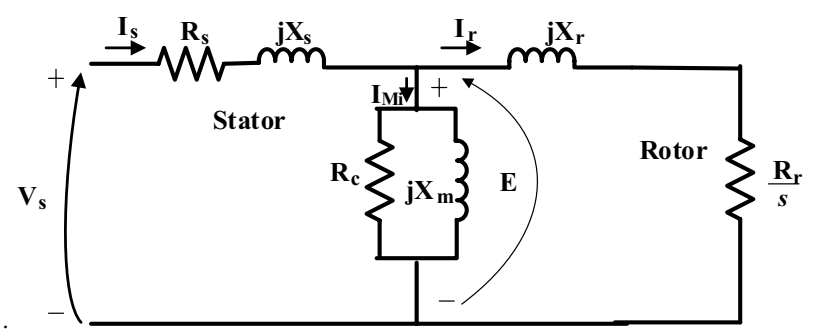

Fig. 1 Per phase equivalent diagram of a three-phase induction motor 


\section{Related work}

Data mining entails the extraction of useful and unknown information from a dataset via data selection, pattern recognition and analysis. Data mining comprises both statistics and machine learning approach to data analysis. As proposed by Azevedo [22], data mining can be referred to as knowledge discovery in databases [2]. It entails the use of computer applications for performing hypothesis testing, regression studies, classification, data clustering, machine learning, data visualization etc. toward identifying any hidden meaningful pattern in the dataset.

On a data mining platform, various algorithms are usually available for carrying out investigative studies on a given dataset. These algorithms include k-means algorithm, multi-layer perceptron, the apriori algorithm, pagerank, adaboost, C4.5, support vector machines [23], expectation maximization algorithm, naive bayes, k-nearest neighbour (kNN), linear regression and so forth. Identifying useful data pattern from a dataset implies discovering the data structure or fitting the data to a model, in order to acquire knowledge from the dataset. A descriptive workflow of a typical data mining process is depicted in Fig. 2. The features in the dataset must be well understood to enable appropriate data selection for the data mining process. According to [24], data preparation comprises data selection, data cleaning, the construction of data, data integration and the formatting of data. Data preparation enables the conversion of the raw dataset into a fit-for-purpose data miming resource.

Data analytics has found application in various fields such as energy management, business management, education etc. In the manufacturing industry, predictive data analytics is now being applied for process optimization across the design, manufacturing and supply stages of the product cycle; a concept referred to as smart manufacturing. Data mining method has also been applied in tracing power grid fault. In the study by Wang et al. [25], a model for collecting power system fault data was developed for fault diagnosis using a decision tree.

A data mining model was implemented by Çakır et al. [2] for predicting voltage unbalance on a TPIM using the Waikato Environment for Knowledge Analysis (Weka) application by detecting stator current at $(1+2 \mathrm{~s}) \mathrm{f} \mathrm{com-}$ ponent and at $2 \mathrm{f}$ component in the motor current spectrum. The performance of the model was evaluated using $\mathrm{R}^{2}$ value; a maximum value of 0.9639 was achieved. An Artificial Neutral Network (ANN) model was applied by Okelola and Elijah [20] for identifying voltage unbalance condition using the operational motor dataset. The performance of the model was assessed using the mean square error (MSE). The feasibility of predicting the parameters of an induction motor by applying the adaptive neurofuzzy inference system was also demonstrated by [26]. The KNIME platform, which was applied in this study has previously being applied for electrical fault related studies. In the study by Yu et al. [27], KNIME was applied for predicting the faults of an oil-immersed transformer. The model implemented was trained with historical fault data and an accuracy of $80 \%$ was achieved with test data.

\section{Methodology}

In this study, the KNIME analytics application was applied to extract useful information from the MATLAB simulated TPIM operational dataset. Data mining algorithms were deployed to implement a supervised learning workflow,

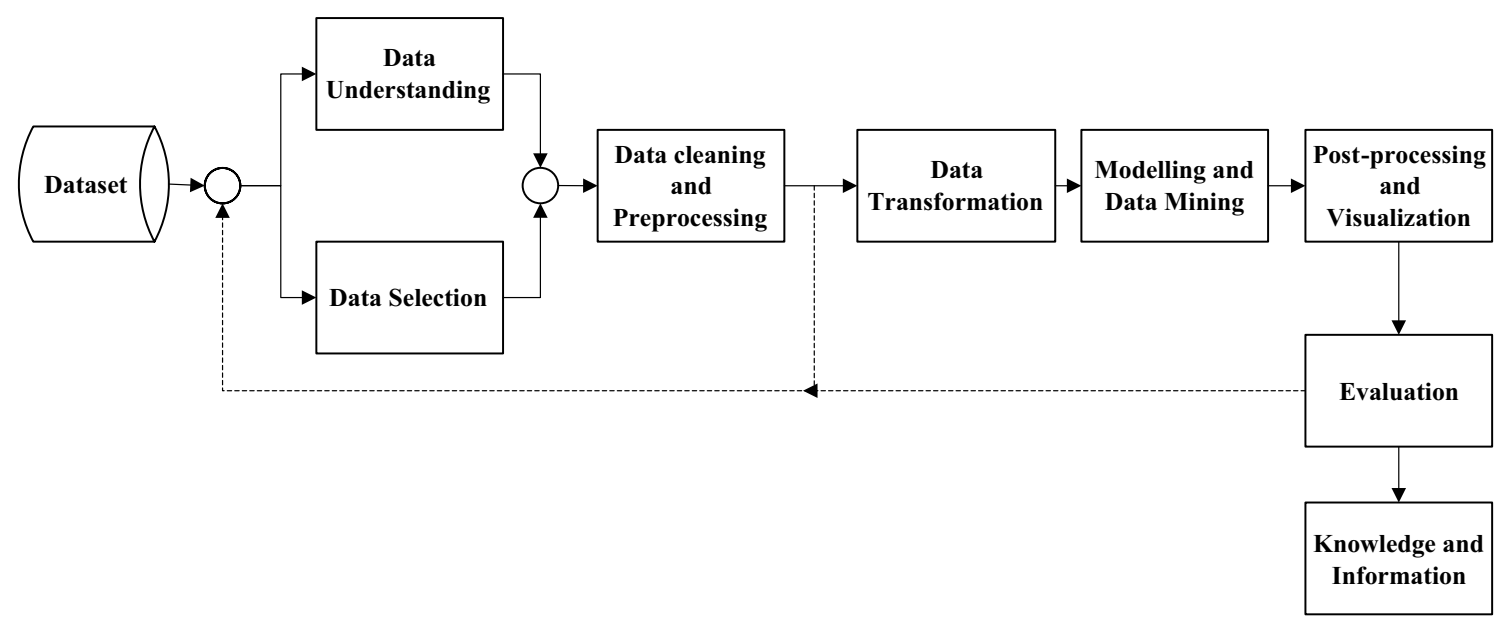

Fig. 2 A typical data mining process 
and this was further supported with analysis using Support Vector Machine on Orange data mining platform. KNIME is a renowned tool that utilizes visual data pipeline workflows, and it has been applied globally for various data mining projects $[27,28]$ by creating visual data flows on the KNIME platform for various analysis. The data mining model displayed in Fig. 3 was deployed for predicting the voltage status of the TPIM using the Tree Ensemble, Decision Tree, and Random Forest predictive algorithms. These algorithms have been extensively, and reliably used in various studies to analyse different types of data. The Decision Tree is intuitive and easy to interpret, it mimics human decision process and performs well without data scaling. The Random Forest develops multiple decision trees by applying randomly selected bootstrap samples. It presents an average result from subset trees, and this reduces variance and overfitting. The Tree Ensemble is similar to the Random Forest. It also works by developing an ensemble of decision trees toward improving the overall model performance. SVM is also a robust algorithm that provides good generalization, and can handle large and sparse datasets. SVM is a discriminative classifier and requires optimal parameter tuning to perform well. The decision Tree was configured to run using a minimum of two records per node, and no pruning method was applied. Tree Ensemble and the Random Forest nodes were executed using the default settings on KNIME. The dataset analysed contains key performance parameters of the TPIM generated as the motor runs under varying voltage supply conditions. The dataset was normalized using the maximum value for each parameter in order to avoid any magnitude-based bias. These parameters are listed as follows; the stator current, the rotor current, the stator and rotor resistive winding losses, the real, reactive and apparent input power, the slip, the power factor, the electromechanical power and the air gap power.

Each complete sample set of the motor performance data was assigned a voltage status which may be balanced under voltage supply (10\%UV, $8 \% \mathrm{UV}, 6 \% \mathrm{UV}, 4 \% \mathrm{UV}$, and $2 \%$ UV), balanced rated voltage (BV), and balanced over voltage supply ( $2 \% \mathrm{OV}, 4 \% \mathrm{OV}, 6 \% \mathrm{OV}, 8 \% \mathrm{OV}$, and $10 \% \mathrm{OV})$. The dataset contains 550 samples which were partitioned into two using stratified sampling which ensures similar percentage of all categories in both training and test samples. $70 \%$ of the samples were applied for training the model while the remaining $30 \%$ served as the validation test data. The Tree Ensemble, the Decision Tree and the Random Forest predictive algorithms were applied separately in order to develop a comparative performance analysis of the three algorithms. The performances of the three algorithms were further verified using Support Vector Machine (SVM) for a stratified sampling experiment with the penalty term set to 1 , and the complexity bound value set to 0.75 using radial basis function (RBF) kernel.

\section{Results of the predictive modelling}

The dataset was processed and prepared for data mining analysis. The KNIME model was able to identify the statistical properties of each parameter, and also the relationship among the performance parameters. Using the acquired

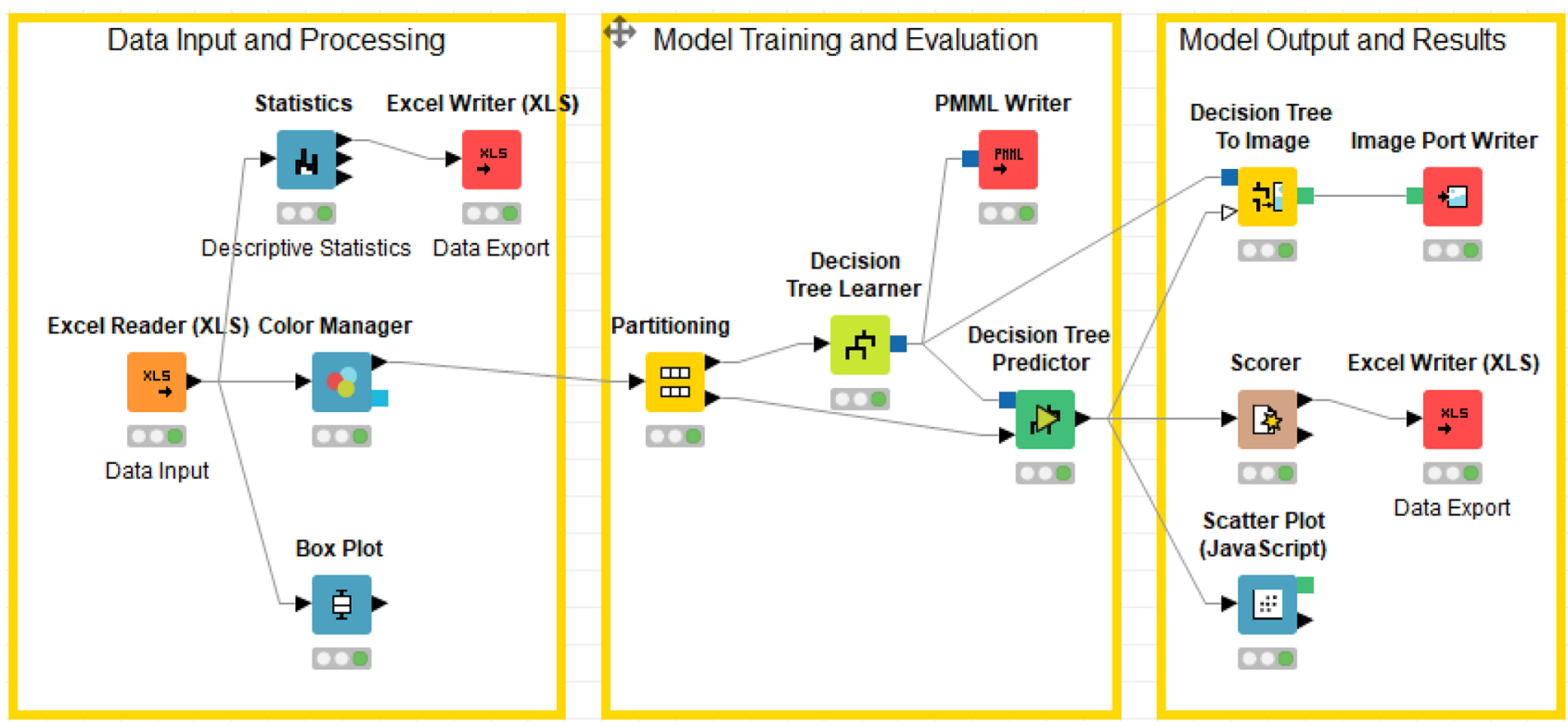

Fig. 3 Supply voltage status predictive KNIME workflow 


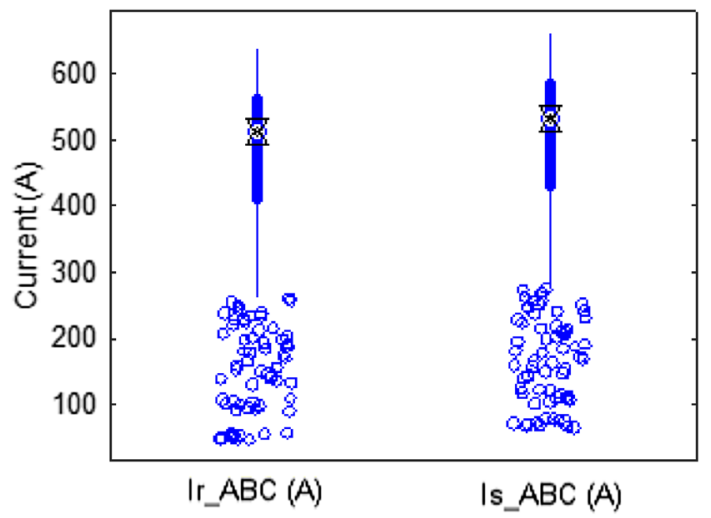

Fig. 4 A box plot of the rotor and stator currents

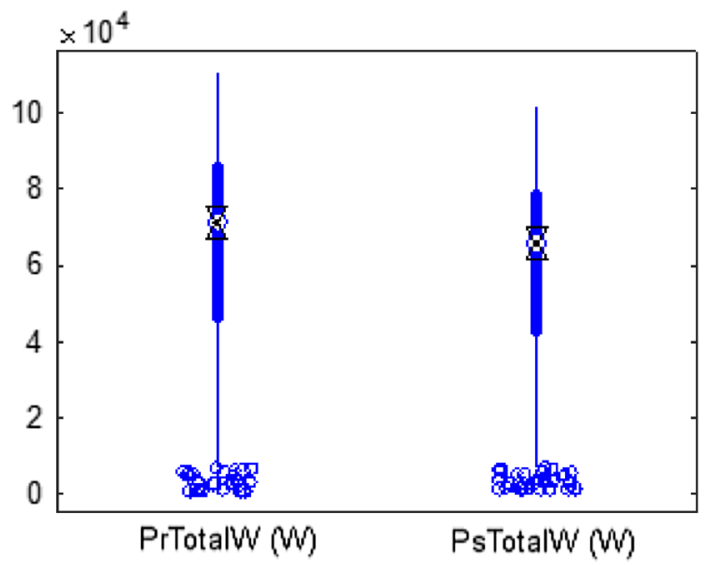

Fig. 5 A box plot of the stator and rotor resistive winding losses

knowledge, the model was able to make a fairly accurate voltage status classification for the evaluated test data.

Figure 4 shows the variation of the stator and rotor currents across 4 quartiles; the lowest value, the lower quartile, the average value, the upper quartile and the highest current value. The rotor current magnitude varied from 44.905 to $638.22 \mathrm{~A}$ while the stator current increased from $62.985 \mathrm{~A}$ to the maximum value of $662.71 \mathrm{~A}$ as the motor slip varied from the starting point at slip $=1$. From the length of each of the quartiles, it was observed that the majority of the current data samples are below the 25th percentile. This implies that, after the initial high current during starting normalizes, the rotor and the stator currents during the bulk of the operational time is well below the average motor current.

The box plot of Fig. 5 presents the variation of the stator and rotor resistive winding losses as the motor operates from $10 \% \mathrm{UV}$ to $\mathrm{BV}$, and then in steps of $2 \%$ all the way to $10 \% \mathrm{OV}$. More energy losses was incurred by the rotor, with a maximum loss of $110931.27 \mathrm{~W}$ while the maximum loss in the stator is $101997.85 \mathrm{~W}$. The difference is due to the significant increase in the rotor current as compared with the stator current. In Fig. 6 , the changes in torque values are displayed as a box plot. Figure 6 shows the torque variations for each voltage status; from under voltage (2-10\%) to over voltage (2-10\%). The power factor varied from the minimum value of 0.41 to the maximum value to 0.88 , while a minimum torque of $174.8 \mathrm{Nm}$, an average torque of $845.16 \mathrm{Nm}$, and a breakdown torque of $1,392.28 \mathrm{Nm}$ were recorded.

In Fig. 7, the power related performance parameters of the motor are shown. The apparent power (VA), the real input power $(W)$, the reactive power (VAR), the air gap power (W) and the electromagnetic power (W) of the motor are plotted for comparative analysis. Figures 8, 9 and 10 shows the variation of the real, reactive an apparent input power of the motor respectively. In Fig. 8, as the simulated motor progressively ran from the starting slip of 1 towards 0.02 , the real power initially increased for doing useful work, and then decreased as the motor speed approached the maximum value at slip $=0$. From Figs. 9 and 10, the reactive and apparent power started reducing from the maximum value immediately after starting at slip $=1$. The maximum reactive input power is 478755.06 VAR as compared with the maximum useful real input power of $275227.08 \mathrm{~W}$ and this emphasizes the need to ensure that TPIMs are in good working condition, connected to a quality power supply and operated with the proper control and starting methods. This will prevent unproductive consumption of reactive power, which also causes line voltage variation on the power network to which such heavy duty motors are connected. Typically, TPIM operates on a load at a slip that is less than 0.1 at the rated load region. Hence, the high magnitude of the reactive energy demand at start up is a huge threat to the motor's life span, and effort must be put in place to ensure that the time taken to progress from start up to the normal load region is extremely short. Also, the starting current must be adequately reduced using appropriate TPIM starting methods. At each slip value, it can be seen from Figs. 8, 9, and 10 that the value of the power consumption increases from $10 \%$ UV to $10 \%$ OV which implies that, at overvoltage conditions the TPIM consumes more energy which increases the energy cost. Like the power consumption, the rotor and the stator resistive losses also increase as current increases with increasing voltage.

The performance of the data mining algorithms deployed for the predictive analysis is presented in Sects. 5.1, 5.2, 5.3, and 5.4. 


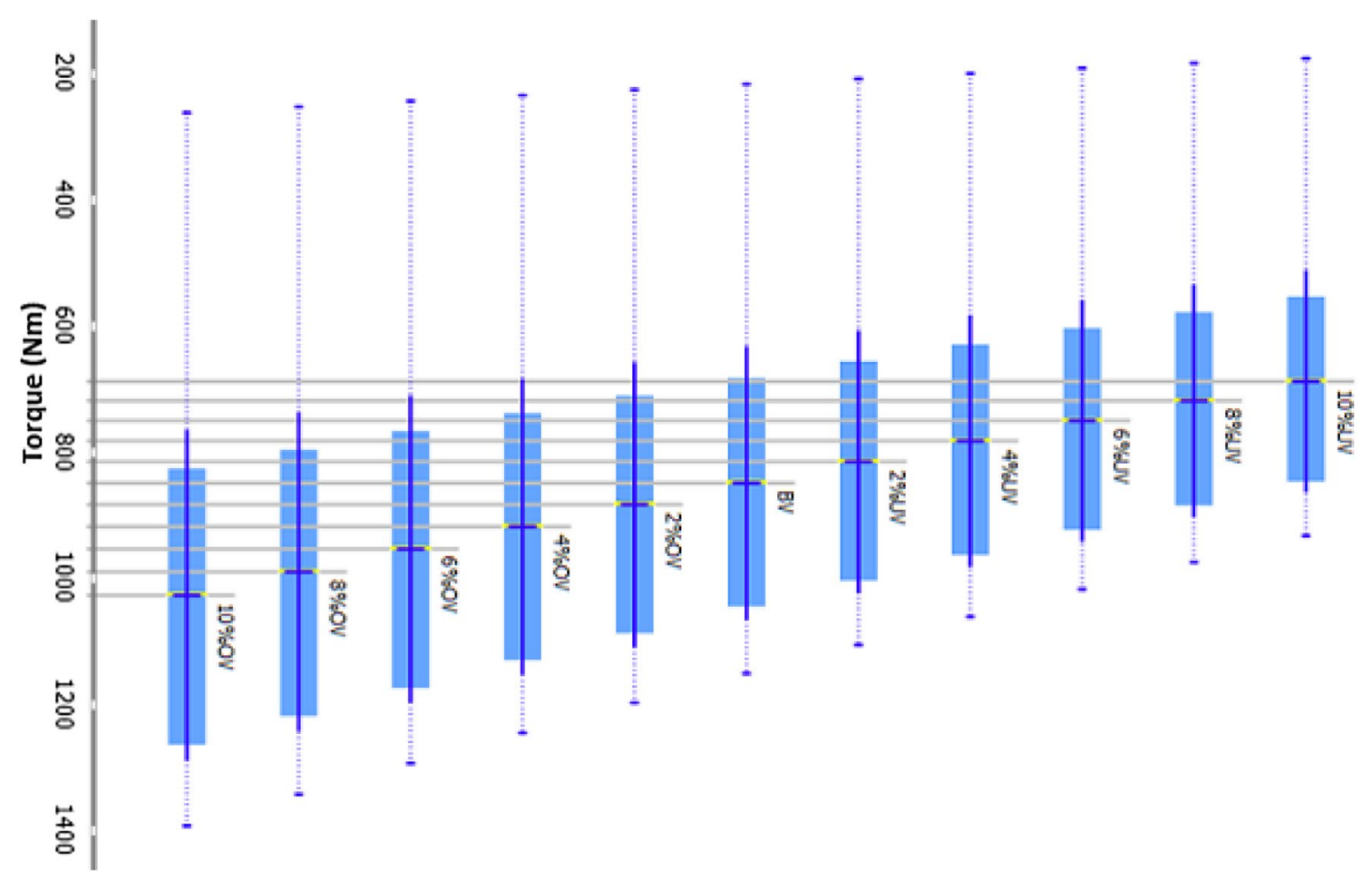

Fig. 6 A box plot showing torque variations for each voltage status

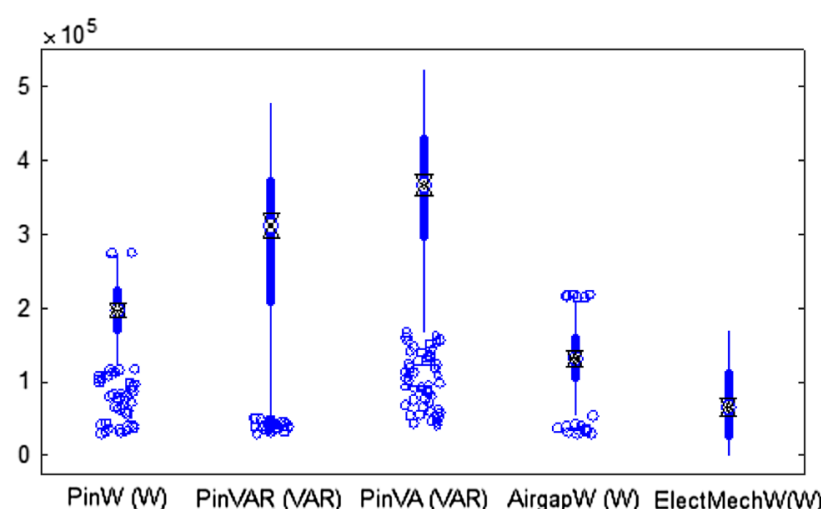

Fig. 7 A box plot showing the variation of the power parameters

\subsection{Tree ensemble predictor}

The tree ensemble algorithm uses a combination of multiple decision trees in order to enhance its prediction accuracy; this implies that the ensemble algorithm combines a group of weak learners to generate a more robust, and improved aggregate predictor. Using the tree ensemble predictor, an accuracy of $80 \%$ was achieved, with Cohen's Kappa value of 0.78 . Table 1 shows the confusion matrix for the tree ensemble algorithm.

\subsection{The decision tree predictor}

Using the decision tree predictor, an accuracy of $74.55 \%$ was achieved, with Cohen's Kappa value of 0.72. Table 2 shows the confusion matrix for the decision tree algorithm.

\subsection{The random forest predictor}

Using the random forest predictor, an accuracy of $81.21 \%$ was achieved with Cohen's Kappa value of 0.793. Table 3 shows the confusion matrix for the random forest algorithm.

\subsection{Support vector machine (SVM)}

The cross validation using SVM had an accuracy of $84.85 \%$, with Cohen's Kappa value of 0.836 . The confusion matrix for the SVM is presented in Table 4.

\subsection{Summary of the models' prediction accuracy}

The performance comparison of the algorithms is summarized in Tables 5 and 6 . The result shows that the SVM had the highest accuracy value of $84.85 \%$ and a minimum error of $15.15 \%$. Also, Table 5 shows that model evaluation test samples at $6 \%$ UV were the only cases with $100 \%$ 


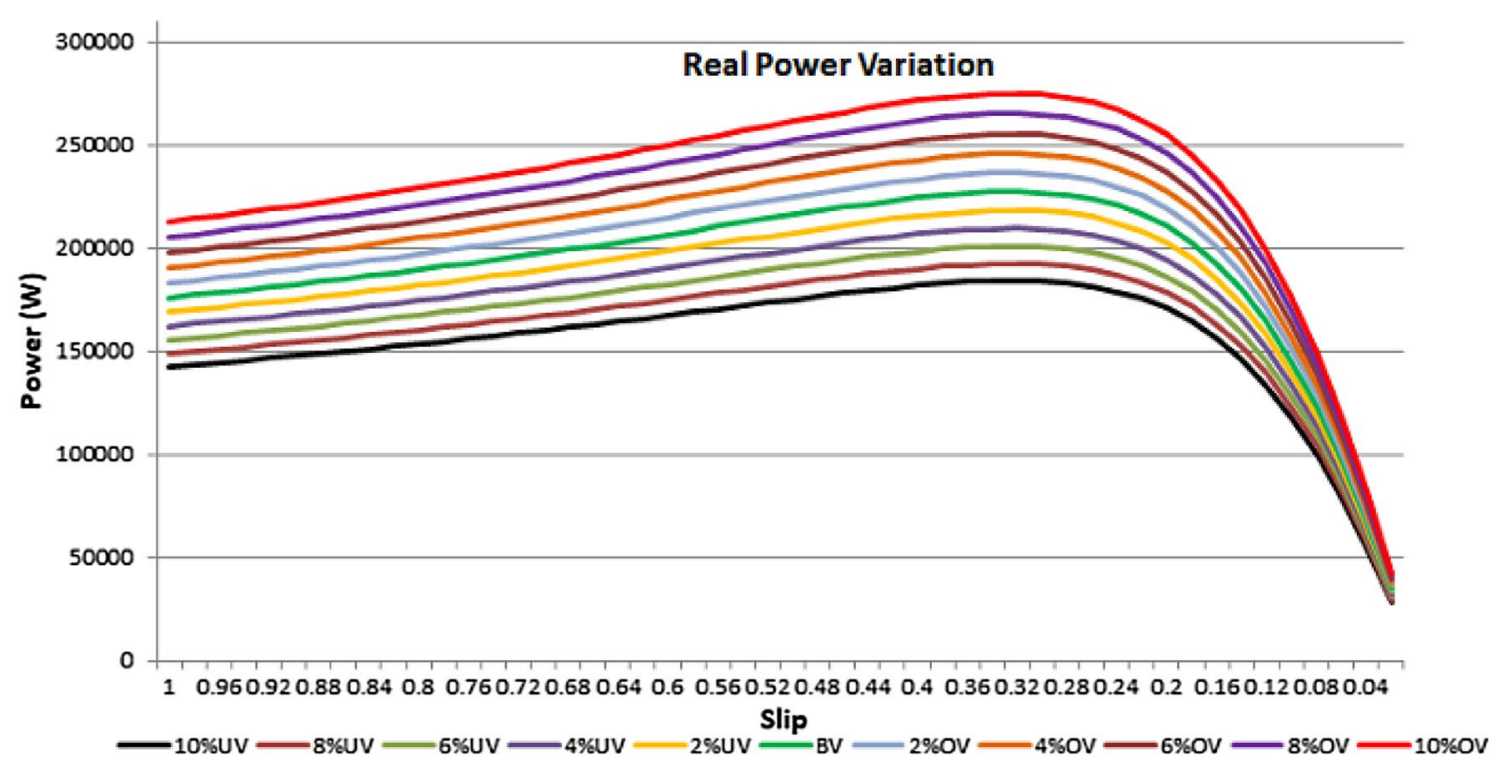

Fig. 8 A plot showing the variation of the real input motor power

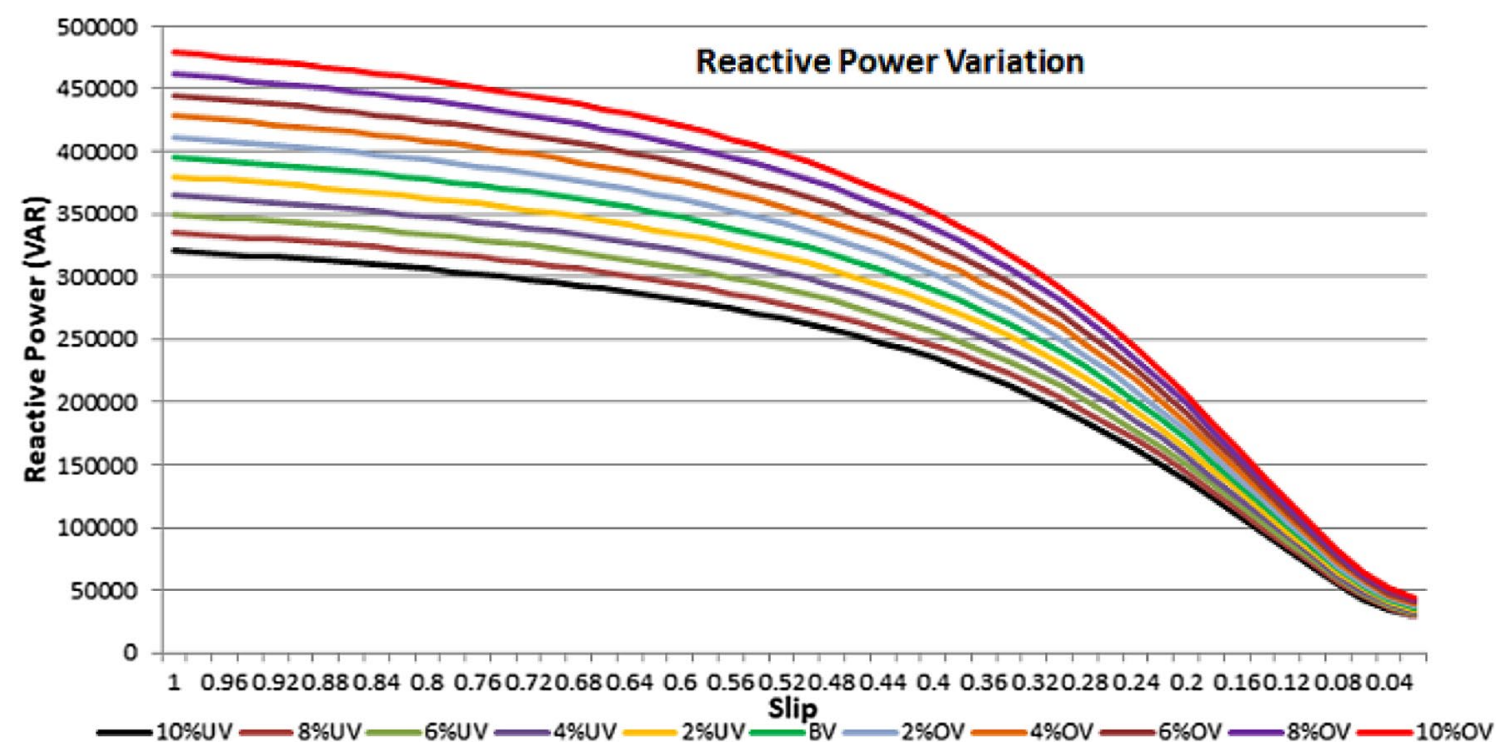

Fig. 9 A plot showing the variation of the reactive input power

prediction accuracy for the Tree Ensemble, the Decision Tree, and the Random Forest algorithms.

\section{Conclusion}

Power quality measure is a vital index that affects the operational performance of three phase induction motors. Power supply variations below, and above the rated voltage of a three-phase induction motor causes undesirable fluctuations in the value of the motor's operational parameters, and this affects the reliability and service life of the motor. The resistive, stator and rotor winding losses of a TPIM increase with increasing supply voltage due to the increased motor current. The energy consumption of the motor also increases with increasing supply voltage i.e. both the true and the reactive input power increases, and this increases energy cost. To ensure optimal performance of the three-phase induction motor, the status of the power supply must be adequately monitored so as to allow for prompt and adequate intervention when extreme cases of supply variations are detected. 


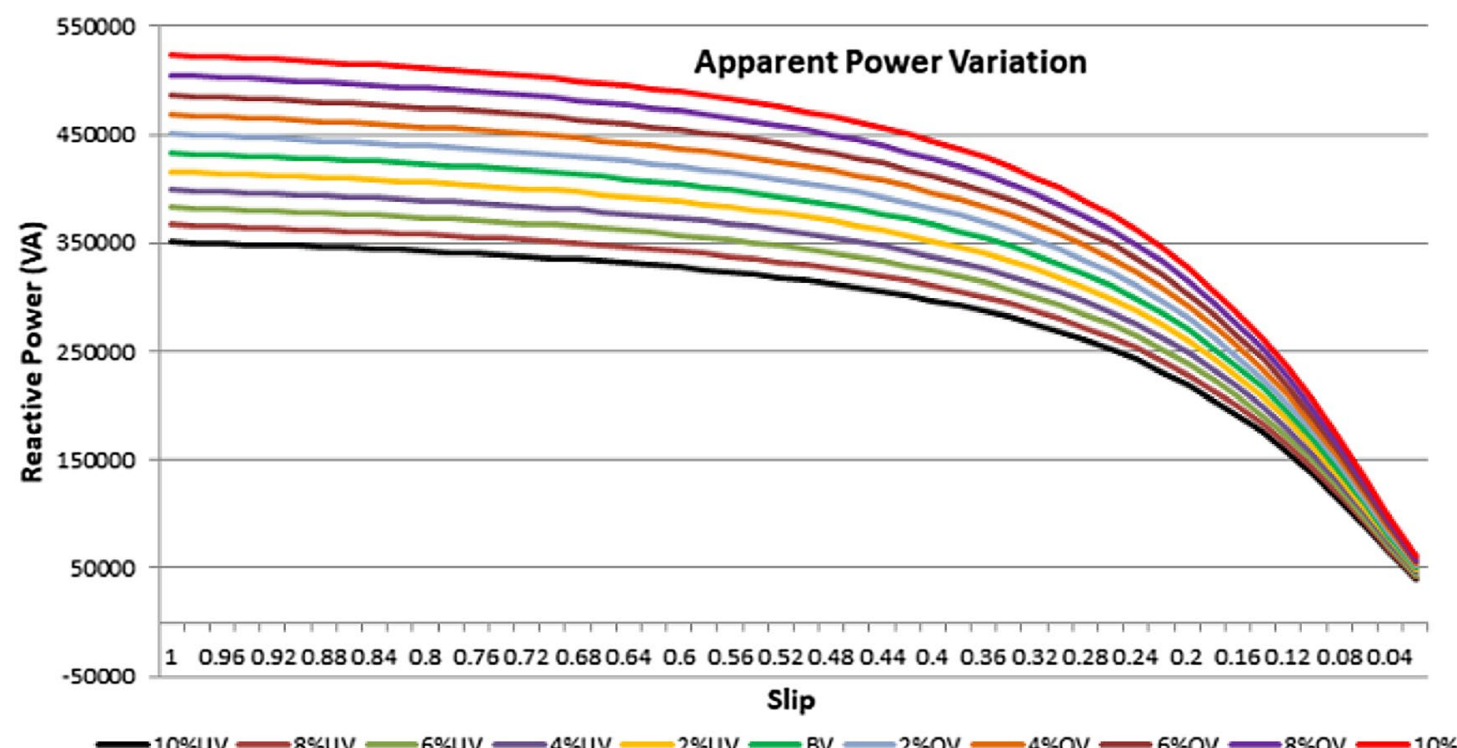

Fig. 10 A plot showing the variation of the motor's apparent input power

Table 1 Confusion matrix of the tree ensemble predictor

Table 2 The confusion matrix of the decision tree predictor

\begin{tabular}{|c|c|c|c|c|c|c|c|c|c|c|c|}
\hline & $10 \%$ UV & $8 \%$ UV & $6 \%$ UV & 4\%UV & $2 \%$ UV & BV & $2 \% \mathrm{OV}$ & $4 \% \mathrm{OV}$ & $6 \% \mathrm{OV}$ & $8 \% \mathrm{OV}$ & $10 \% \mathrm{OV}$ \\
\hline $10 \%$ UV & 13 & 2 & 0 & 0 & 0 & 0 & 0 & 0 & 0 & 0 & 0 \\
\hline $8 \%$ UV & 2 & 13 & 0 & 0 & 0 & 0 & 0 & 0 & 0 & 0 & 0 \\
\hline $6 \%$ UV & 0 & 2 & 12 & 1 & 0 & 0 & 0 & 0 & 0 & 0 & 0 \\
\hline $4 \%$ UV & 0 & 0 & 0 & 13 & 2 & 0 & 0 & 0 & 0 & 0 & 0 \\
\hline $2 \%$ UV & 0 & 0 & 0 & 6 & 9 & 0 & 0 & 0 & 0 & 0 & 0 \\
\hline BV & 0 & 0 & 0 & 0 & 4 & 10 & 1 & 0 & 0 & 0 & 0 \\
\hline $2 \% \mathrm{OV}$ & 0 & 0 & 0 & 0 & 0 & 1 & 13 & 1 & 0 & 0 & 0 \\
\hline $4 \% \mathrm{OV}$ & 0 & 0 & 0 & 0 & 0 & 0 & 1 & 13 & 1 & 0 & 0 \\
\hline $6 \% \mathrm{OV}$ & 0 & 0 & 0 & 0 & 0 & 0 & 0 & 1 & 14 & 0 & 0 \\
\hline $8 \% \mathrm{OV}$ & 0 & 0 & 0 & 0 & 0 & 0 & 0 & 0 & 3 & 11 & 1 \\
\hline $10 \% \mathrm{OV}$ & 0 & 0 & 0 & 0 & 0 & 0 & 0 & 1 & 1 & 2 & 11 \\
\hline
\end{tabular}

\begin{tabular}{|c|c|c|c|c|c|c|c|c|c|c|c|}
\hline & $10 \%$ UV & $8 \%$ UV & $6 \%$ UV & $4 \%$ UV & $2 \% U V$ & BV & $2 \% \mathrm{OV}$ & $4 \% \mathrm{OV}$ & $6 \% \mathrm{OV}$ & $8 \% \mathrm{OV}$ & $10 \% \mathrm{OV}$ \\
\hline $10 \%$ UV & 12 & 2 & 0 & 0 & 1 & 0 & 0 & 0 & 0 & 0 & 0 \\
\hline 8\%UV & 2 & 13 & 0 & 0 & 0 & 0 & 0 & 0 & 0 & 0 & 0 \\
\hline $6 \%$ UV & 0 & 5 & 10 & 0 & 0 & 0 & 0 & 0 & 0 & 0 & 0 \\
\hline 4\%UV & 0 & 0 & 0 & 14 & 1 & 0 & 0 & 0 & 0 & 0 & 0 \\
\hline $2 \%$ UV & 2 & 0 & 0 & 3 & 10 & 0 & 0 & 0 & 0 & 0 & 0 \\
\hline BV & 1 & 0 & 0 & 0 & 4 & 9 & 1 & 0 & 0 & 0 & 0 \\
\hline $2 \% \mathrm{OV}$ & 0 & 0 & 0 & 0 & 1 & 2 & 11 & 1 & 0 & 0 & 0 \\
\hline $4 \% \mathrm{OV}$ & 0 & 0 & 0 & 0 & 0 & 0 & 2 & 12 & 1 & 0 & 0 \\
\hline $6 \% \mathrm{OV}$ & 0 & 0 & 0 & 1 & 0 & 0 & 0 & 2 & 11 & 1 & 0 \\
\hline $8 \% \mathrm{OV}$ & 0 & 0 & 0 & 0 & 0 & 1 & 0 & 2 & 1 & 11 & 0 \\
\hline $10 \% \mathrm{OV}$ & 0 & 0 & 0 & 0 & 1 & 0 & 1 & 1 & 0 & 2 & 10 \\
\hline
\end{tabular}


Table 3 The confusion matrix of the random forest predictor

Table 4 The confusion matrix of the support vector machine

\begin{tabular}{|c|c|c|c|c|c|c|c|c|c|c|c|}
\hline & $10 \%$ UV & $8 \%$ UV & $6 \%$ UV & $4 \%$ UV & $2 \% U V$ & BV & $2 \% \mathrm{OV}$ & $4 \% \mathrm{OV}$ & $6 \% \mathrm{OV}$ & $8 \% \mathrm{OV}$ & $10 \% \mathrm{OV}$ \\
\hline $10 \%$ UV & 13 & 2 & 0 & 0 & 0 & 0 & 0 & 0 & 0 & 0 & 0 \\
\hline $8 \%$ UV & 2 & 13 & 0 & 0 & 0 & 0 & 0 & 0 & 0 & 0 & 0 \\
\hline 6\%UV & 0 & 0 & 14 & 1 & 0 & 0 & 0 & 0 & 0 & 0 & 0 \\
\hline 4\%UV & 0 & 0 & 0 & 13 & 2 & 0 & 0 & 0 & 0 & 0 & 0 \\
\hline $2 \% U V$ & 0 & 0 & 0 & 6 & 9 & 0 & 0 & 0 & 0 & 0 & 0 \\
\hline BV & 0 & 0 & 0 & 0 & 2 & 10 & 3 & 0 & 0 & 0 & 0 \\
\hline $2 \% \mathrm{OV}$ & 0 & 0 & 0 & 0 & 0 & 1 & 14 & 0 & 0 & 0 & 0 \\
\hline $4 \% \mathrm{OV}$ & 0 & 0 & 0 & 0 & 0 & 0 & 1 & 12 & 2 & 0 & 0 \\
\hline $6 \% \mathrm{OV}$ & 0 & 0 & 0 & 0 & 0 & 0 & 0 & 2 & 13 & 0 & 0 \\
\hline $8 \% \mathrm{OV}$ & 0 & 0 & 0 & 0 & 0 & 0 & 1 & 0 & 2 & 11 & 1 \\
\hline $10 \% \mathrm{OV}$ & 0 & 0 & 0 & 0 & 0 & 0 & 0 & 1 & 1 & 1 & 12 \\
\hline
\end{tabular}

\begin{tabular}{|c|c|c|c|c|c|c|c|c|c|c|c|}
\hline & $10 \%$ UV & $8 \%$ UV & $6 \%$ UV & $4 \%$ UV & $2 \%$ UV & BV & $2 \% \mathrm{OV}$ & $4 \% \mathrm{OV}$ & $6 \% \mathrm{OV}$ & $8 \% \mathrm{OV}$ & $10 \% \mathrm{OV}$ \\
\hline $10 \%$ UV & 13 & 0 & 2 & 0 & 0 & 0 & 0 & 0 & 0 & 0 & 0 \\
\hline 8\%UV & 1 & 12 & 2 & 0 & 0 & 0 & 0 & 0 & 0 & 0 & 0 \\
\hline $6 \%$ UV & 0 & 0 & 14 & 0 & 0 & 0 & 0 & 0 & 0 & 1 & 0 \\
\hline 4\%UV & 1 & 0 & 2 & 12 & 0 & 0 & 0 & 0 & 0 & 0 & 0 \\
\hline $2 \% U V$ & 0 & 0 & 1 & 0 & 14 & 0 & 0 & 0 & 0 & 0 & 0 \\
\hline BV & 1 & 0 & 1 & 0 & 1 & 12 & 0 & 0 & 0 & 0 & 0 \\
\hline $2 \% \mathrm{OV}$ & 1 & 0 & 0 & 0 & 0 & 1 & 13 & 0 & 0 & 0 & 0 \\
\hline $4 \% \mathrm{OV}$ & 0 & 0 & 0 & 0 & 1 & 0 & 1 & 13 & 0 & 0 & 0 \\
\hline $6 \% \mathrm{OV}$ & 1 & 0 & 0 & 0 & 1 & 0 & 0 & 1 & 12 & 0 & 0 \\
\hline $8 \% \mathrm{OV}$ & 1 & 0 & 0 & 0 & 1 & 0 & 0 & 0 & 1 & 12 & 0 \\
\hline $10 \% \mathrm{OV}$ & 0 & 0 & 1 & 0 & 0 & 0 & 0 & 1 & 0 & 0 & 13 \\
\hline
\end{tabular}

Table 5 Prediction confusion of the data mining algorithms

\begin{tabular}{|c|c|c|c|c|c|c|c|c|}
\hline & \multicolumn{2}{|l|}{ Tree ensemble } & \multicolumn{2}{|l|}{ Decision tree } & \multicolumn{2}{|l|}{ Random forest } & \multicolumn{2}{|l|}{ SVM } \\
\hline & True positives & False positives & True positives & True positives & True positives & False positives & True positives & False positives \\
\hline $10 \%$ UV & 13 & 2 & 12 & 5 & 13 & 2 & 13 & 2 \\
\hline $8 \%$ UV & 13 & 4 & 13 & 7 & 13 & 2 & 12 & 3 \\
\hline $6 \%$ UV & 12 & 0 & 10 & 0 & 14 & 0 & 14 & 1 \\
\hline $4 \% U V$ & 13 & 7 & 14 & 4 & 13 & 7 & 12 & 3 \\
\hline $2 \% U V$ & 9 & 6 & 10 & 8 & 9 & 4 & 14 & 1 \\
\hline BV & 10 & 1 & 9 & 3 & 10 & 1 & 12 & 3 \\
\hline $2 \% \mathrm{OV}$ & 13 & 2 & 11 & 4 & 14 & 5 & 13 & 2 \\
\hline $4 \% \mathrm{OV}$ & 13 & 3 & 12 & 6 & 12 & 3 & 13 & 2 \\
\hline $6 \% \mathrm{OV}$ & 14 & 5 & 11 & 2 & 13 & 5 & 12 & 3 \\
\hline $8 \% \mathrm{OV}$ & 11 & 2 & 11 & 3 & 11 & 1 & 12 & 3 \\
\hline $10 \% \mathrm{OV}$ & 11 & 1 & 10 & 0 & 12 & 1 & 13 & 2 \\
\hline Overall & 132 & 33 & 123 & 42 & 134 & 31 & 140 & 25 \\
\hline
\end{tabular}

This study evaluates the feasibility of applying data mining techniques for predicting the instantaneous operational status of a three-phase induction motor in terms of the voltage supply condition. By using simulated operational motor performance data, a KNIME-based predictive model was trained with $70 \%$ of the total sample using the tree ensemble, the decision tree, and the random forest algorithm. The performance of the trained model was evaluated with the remaining $30 \%$ of the data sample. The result from the three algorithms was further investigated 
Table 6 Comparison of the performance of the data mining algorithms

\begin{tabular}{|c|c|c|c|c|}
\hline & $\begin{array}{l}\text { Tree ensem- } \\
\text { ble }\end{array}$ & Decision tree & $\begin{array}{l}\text { Random } \\
\text { forest }\end{array}$ & SVM \\
\hline $\begin{array}{l}\text { Correct clas- } \\
\text { sified }\end{array}$ & 132 & 123 & 134 & 140 \\
\hline Accuracy (\%) & 80 & 74.55 & 81.21 & 84.85 \\
\hline $\begin{array}{l}\text { Cohen's } \\
\text { Kappa (k) }\end{array}$ & 0.78 & 0.72 & 0.793 & 0.836 \\
\hline $\begin{array}{l}\text { Wrong classi- } \\
\text { fied }\end{array}$ & 33 & 42 & 31 & 25 \\
\hline Error (\%) & 20 & 25.45 & 18.79 & 15.15 \\
\hline
\end{tabular}

using support vector machine. The result shows that the SVM algorithm had the highest accuracy of $84.85 \%$. The motor's operational status, model-evaluation test sample sets were classified has been under voltage (10\%UV, $8 \% \mathrm{UV}$, $6 \% \mathrm{UV}, 4 \% \mathrm{UV}$, and $2 \% \mathrm{UV}$ ), balanced rated voltage (BV), and balanced over voltage supply $(2 \% \mathrm{OV}, 4 \% \mathrm{OV}, 6 \% \mathrm{OV}$, $8 \% \mathrm{OV}$, and $10 \% \mathrm{OV}$ ) operational voltage conditions. The model accuracy is indicative of the possibility of deploying real time instantaneous three phase induction motor diagnostic devices, which have been trained using knowledge acquired by data mining historical motor performance dataset for voltage status, and other motor performance monitoring. This may be applied for activating appropriate control measures to mitigate the implication of any arising voltage supply fluctuations. By using applicable training dataset, this method can be applied to different TPIM of various power ratings. Also, further studies can be carried out to determine the possibility for torque and speed control of TPIM using knowledge acquired from data mining. With the results of this study on TPIM, it can be inferred that there are still many other potential applications of data mining and knowledge discovery from datasets in engineering.

\section{Compliance with ethical standards}

Conflict of interest On behalf of all authors, the corresponding author states that there is no conflict of interest.

\section{References}

1. Taha H, Ammar M, Moustafa Hassan M (2016) Induction motors stator fault analysis based on artificial intelligence. Indones $J$ Electr Eng Comput Sci 2:69-78. https://doi.org/10.11591/ijeec s.v2.i1.pp69-78

2. Çakır A, Çalış H, Küçüksille EU (2009) Data mining approach for supply unbalance detection in induction motor. Expert Syst Appl 36(9):11808-11813
3. Oyedepo O, Adaramola M, Odunfa M, Aremu O (2015) Analysis of energy utilization in selected industries in Southwestern Nigeria. Energy Eng 112(6):47-74

4. Quispe E, Gonzalez G, Aguado J (2004) Influence of unbalanced and waveform voltage on the performance characteristics of three-phase induction motors. In: International conference on renewable energy and power quality, Barcelona

5. IEO (2018) International Energy Outlook 2018 Executive Summary

6. Pillay $P$, Hofmann $P$, Manyage $M$ (2002) Derating of induction motors operating with a combination of unbalanced voltages and over or undervoltages. IEEE Trans Energy Conserv 17(4):485-491

7. Kersting WH (2000) Causes and effects of unbalanced voltages serving an induction motor. In: Rural electric power conference Louisville, KY, IEEE

8. Adekitan IA, AbdulKareem A (2019) The significance of the mode of voltage imbalance on the operation and energy losses of 3-phase induction motor. Eng Appl Sci Res 46(3):200-209

9. Gafford BN, Duesterhoeft WC, Mosher CC (1959) Heating of Induction Motors on Unbalanced. Tran Am Inst Electr Eng Part III Power Appar Syst 78(3):282-286

10. Williams JE (1954) Operation of 3-phase induction motors on unbalanced voltages [includes discussion]. Trans Am Inst Electr Eng Part III Power Appar Syst 73(1):1. https://doi.org/10.1109/ AIEEPAS.1954.4498802

11. Gnacinski $P$ (2008) Effect of unbalanced voltage on windings temperature, operational life and load carrying capacity of induction machine. Energy Convers Manag 49(4):761-770. https ://doi.org/10.1016/j.enconman.2007.07.033

12. De Oliveira J, Neto L, Ribeiro P (1998) Power quality impact on performance and associated costs of three-phase induction motors. In: 8th international conference on harmonics and quality of power. Proceedings, pp 791-797, IEEE

13. Awelewa AA, Mbamaluikem PO, Samuel IA (2017) Artificial neural networks for intelligent fault location on the 33-Kv Nigeria transmission line. Int J Eng Trends Technol 54(3):147-155. https ://doi.org/10.14445/22315381/IJETT-V54P221

14. Kareem OK, Adekitan Al, Awelewa A (2019) Power distribution system fault monitoring device for supply networks in Nigeria. Int J Electr Comput Eng 9(4):2803-2812

15. Glowacz A, Glowacz W, Glowacz Z, Kozik J (2018) Early fault diagnosis of bearing and stator faults of the single-phase induction motor using acoustic signals. Measurement 113:1-9. https://doi. org/10.1016/j.measurement.2017.08.036

16. López-Pérez D, Antonino-Daviu J (2017) Application of infrared thermography to failure detection in industrial induction motors: case stories. IEEE Trans Ind Appl 53(3):1901-1908. https ://doi.org/10.1109/TIA.2017.2655008

17. Sun C, Ma M, Zhao Z, Chen X (2018) Sparse deep stacking network for fault diagnosis of motor. IEEE Trans Industr Inf 14(7):3261-3270. https://doi.org/10.1109/TII.2018.2819674

18. Bazan GH, Scalassara PR, Endo W, Goedtel A, Godoy WF, Palácios RHC (2017) Stator fault analysis of three-phase induction motors using information measures and artificial neural networks. Electr Power Syst Res 143:347-356. https://doi.org/10.1016/j. epsr.2016.09.031

19. Zolfaghari M, Taher SA, Munuz DV (2016) Neural networkbased sensorless direct power control of permanent magnet synchronous motor. Ain Shams Eng J 7(2):729-740. https://doi. org/10.1016/j.asej.2016.01.002

20. Okelola MO, Elijah O (2018) Detection of voltage unbalance on three phase induction motor using artificial neural network. Int J Emerg Trends Eng Dev. https://doi.org/10.26808/rs.ed.i8v4.03

21. Hsiao C, Liu M Failure mode analysis of induction motor model. In: 2017 International conference on applied system innovation 
(ICASI), pp 25-28, 13-17 May 2017. https://doi.org/10.1109/icasi .2017 .7988336

22. Azevedo A (2018) Data mining and knowledge discovery in databases. In: Encyclopedia of Information Science and Technology, Fourth Edition. IGI Global, pp 1907-1918

23. Ramesh Babu N, Jagan Mohan B (2017) Fault classification in power systems using EMD and SVM. Ain Shams Eng J 8(2):103111. https://doi.org/10.1016/j.asej.2015.08.005

24. Shearer C (2000) The CRISP-DM model: the new blueprint for data mining. J Data Warehous 5(4):13-22

25. Wang L, Shang L, Ma M, Ma Z (2018) Fault diagnosis and trace method of power system based on big data platform. IOP Conf Ser Mater Sci Eng 394:042116. https://doi.org/10.1088/1757899x/394/4/042116

26. Jirdehi MA, Rezaei A (2016) Parameters estimation of squirrel-cage induction motors using ANN and ANFIS. Alex Eng J 55(1):357-368. https://doi.org/10.1016/j.aej.2016.01.026
27. Yu S, Zhao D, Chen W, Hou H (2016) Oil-immersed power transformer internal fault diagnosis research based on probabilistic neural network. Proc Comput Sci 83:1327-1331. https://doi. org/10.1016/j.procs.2016.04.276

28. Wahbeh $\mathrm{AH}, \mathrm{Al}$-Radaideh $\mathrm{QA}, \mathrm{Al}-\mathrm{Kabi} \mathrm{MN}, \mathrm{Al}$-Shawakfa EM (2011) A comparison study between data mining tools over some classification methods. Int J Adv Comput Sci Appl $8(2): 18-26$

Publisher's Note Springer Nature remains neutral with regard to jurisdictional claims in published maps and institutional affiliations. 